\title{
A Review of the Interlanguage on Performance and Competence Representation: Universal Grammar
}

\author{
Qurrata'ain \\ Yogyakarta State University, Indonesia \\ e-mail: qurrataainmahfud@gmail.com \\ Pratomo Widodo \\ Yogyakarta State University, Indonesia \\ e-mail:pratomo@uny.ac.id
}

\begin{abstract}
:
Interlanguage has been the main development of field research on second language acquisition (SLA). According to Richard et al (1996) Interlanguage is one of the kinds of language that can be produced by second language learners in the process of acquiring or learning a new language. The influence of the universal grammar of the first language in learning the second language is still debated whether or not universal grammar takes part in second language acquisition. In this article has the aim to investigate the interlanguage of competence and performance representation. In second language acquisition, there is a confusion between the interlanguage of competence and performance. When people perform the second language, it will different from native speakers and argue that demonstrates defects in competence aspect. So, there is a lack of universal grammar. Interlanguage is natural when people acquire a second language based on the theory interlanguage. It might have the knowledge of grammar but when the people produced the sentence or words. It will be grammatical errors. There is some performance factor that the second language learners' competence is hidden such as parsing or demands of processing. It differences between pure knowledge and how people use the knowledge of its self. Both of them do not always coincide. This research tried to offer a descriptive review of the Interlanguage on performance and competence representation.
\end{abstract}

Keywords: competence, interlanguage, performance, SLA, universal grammar

\section{Introduction}

The Interlanguage has been the main development of field research on second language acquisition (SLA). Interlanguage has a different on a linguistic system which is the learner's native language and the target language. Interlanguage is a language mistake made by nonnative speakers using a second language. According to Selinker (2009) the term of interlanguage who referred to as second language systematic knowledge independent of first language and second language. According to Richard et al (1996) interlanguage is one of the kinds of language that can be produced by second language learners in the process of acquiring or learning a new 
language. Selinker also explained about the interlanguage identification (1) utterance in the learner's native language that produced by learner (2) interlanguage utterances that produced by the learners and the last is (3) Target language utterances produced by native speakers of the target language. People can analyze the interlanguage happened by a meaningful performance of the learners' native language.

There is a term namely nature that was introduced by Chomsky (1960s) that stated human was born with innate properties and each human has a language acquisition device (LAD). Then, Universal Grammar (UG) became a popular theory. In universal grammar (UG) theory divided into competence and performance. Competence refers to people insight of language while the performance refers to the ability of people to understand and articulate the words or the output of the competence of language. When people have a good competence of language, it makes sure people also are good in performance. The main difference is in competence and performance for example, in Indonesia language and English. This article has the aim to explore how the interlanguage representation is accessed during the processing to know the representation of the differences between competence and performance. It will be related to universal grammar theory which is the universal grammar theory contains two things namely performance and competence in producing second language acquisition. All languages in the world have phrase structure rule and specific information about the language such as tense, the agreement so on. In English syntax also described the grammatical structure so that the universal grammar provided the basis for all human languages and individual language are simply variations on this basic design (Fromkin, et al., 2007). The problem of linguistic competences those are intricate, complex and subtle. The children acquire this linguistic competence which extends in the target language in various ways. People can understand and produce the sentence which they had never heard before however, the dialectical has differences, but the competence of native language learner and native language is similar. So, it means the native language learner achieved in competence grammar. Universal grammar is a principle which constrains the form and function of grammars. The universal grammar theory will give the native language learner more knowledge of complex properties of language. English explains if there is a modal in a sentence so the verb must be a base word (V1) while the Indonesia language is not determined like specific in English. When the learners' native speakers said "Mary can bring two books", it should change Mary can bring two books based on the grammatical of English. In this article has the aim to investigate the interlanguage of competence and performance representation. In second language acquisition, there is a confusion between the interlanguage of competence and performance. The competence focuses on interlanguage in linguistic representation while performance focuses on the representation to understand and produce the language. When people try to show second language performance, it will different from native speakers and argue that demonstrates defects in competence. So, there is a lack of universal grammar. Interlanguage as a human language should be matched with universal grammar language. Actually, the interlanguage is not totally error in the structure of grammatical but it caused factors of the human's mind. As we know, the second language learners are seldom appropriate in native language competence, especially in grammar. It is not grammatical or interlanguage in grammar. In competence, they know all the insight of this grammar but when the people produced the sentence or words. It may be grammatical is an error. There is some performance factor that the second language learners' competence is hidden such as parsing or demands of processing. It differences between pure knowledge and how people use the knowledge it's self. 
Both of them do not always coincide. The most important to know how the interlanguage of competence and performance representation based on the theory of universal grammar in second language acquisition.

The phenomenon of interlanguage is almost interested in researchers. This research builds by previous studies (e.g Cheng, 2015; Popa, 2016; Saric, 2017). The scholars have researched the interlanguage on second language acquisition. Popa (2016) states that second language acquisition influences the mother tongue and the acquisition of the second language. The research tries to find how migration contexts because the diversity of languages has an effect on the process of second language acquisition. It is caused the existence of universal grammar so that the interlanguage happened of the learners. Whereas it was supported by the other research proposed by Saric (2017), the research states that the interlanguage as a dynamic language system that created by second language learners. Thus, the purpose of the research is trying to observe how the language of the learner that learn English and German, Especially the developmental patterns in the interlanguage research. The result of developmental patterns can also be studied by applying obligatory occasion and frequency analysis. From those researches, the writer tries to find investigate interlanguage in competence and performance on second language acquisition. Besides that, Cheng (2015) has the aim to find the interlanguage-based error analysis in higher vocational and technological college EFL education in China. The study claims that the language learner output as a reference context to make errors when the students learn the language. It is related to the output of the learners that identify what learners have understood, the students have not yet or have mastered. It will give an impact on the second language acquisition of the learners.

\section{Universal Grammar (UG) and Second Language Acquisition (SLA)}

Universal grammar is a theory that functions to control the sentences of an utterance. This theory is explained about how people acquire the language generally for all language. The universal grammar language in the world is the same properly (e.g for the verb is to explain what people do, process, or act and each verb is always needed subject and object in the sentence). According to Chomsky stated the knowledge of first language acquisition or mother tongue was derived from the universal grammar which determined the basic design of natural language or first language. The children were born with the capacity or potential of language so that Chomsky believed the children have Language Acquisition Device (LAD). LAD is the most important in acquiring the language of children. The functions of LAD are (1) the ability to distinguish sounds of language and another sound (2) the ability to organize the linguistic units (3) the insight of language system (4) the ability to use the language system based on development linguistic system. Universal grammar also is related to LAD. The universal grammar is a set of discovery principles to relate the general principle provided by first language acquisition. Actually, the native language learners have a structure of the first language that interlink with the principles of universal grammar because of universal grammar as a set for parameters of language. The native language learners also may link in universal grammar directly or not through the first language. There is a big question "what the structure of language in the second language limited as a structure of the first language by universal grammar?" the notion of a parameter in universal grammar has the relationship between first language and second language. The native learners do not know when they do not have more knowledge about it. How do the native language learners able to know the second language itself? For 
example ${ }^{\star}$ is the advertising that on television is good? This sentence is ungrammatical. Both of the languages have the principles of universal grammar. In conclusion, besides the first language is much related to universal grammar as the second language too. According to White (1989) in second language acquisition, there is an interaction between the Universal Grammar and the linguistic input from the language being acquired.

However, there is some case that made universal grammar does not have a link with the native language learners. The universal grammar might not be linked after a certain age of the learners. It related to a critical period. According to Chomsky the critical period is determined limited to acquire the first language between two years old before the children have a strong physical and twelve years old after the brain inflexible. The children at a certain age could not use universal grammar directly. Thus, the native language learners provided many examples of sentences so that it could be helped to learn the second language and operate the universal grammar language. As knowing, the second language, for example, English has a structure of SVO and for "verb" his own rules in sentences based on subject or the events happened in past, present and future. It would be made "verb" in a sentence changed. Chomsky emphasized that the universal grammar language is unique for second language learners but this theory had to take evaluation by linguists in applied linguistics.

There have been many debates about the function of universal grammar in second language acquisition. Universal grammar refers to a grammar that has the same in common all languages. If the second language learners try to access universal grammar actually it would not different when they access universal grammar in the first language. There is a fundamental identity hypothesis By Schwartz (cited in Farahani et al, 2014). This hypothesis contained that the universal theory is also guiding in second language acquisition as first language acquisition. But this hypothesis also emphasized very seldom, the second language learners can achieve like native speakers competence. It might be the LAD is available although it had been passed the critical period. Generally, there are four different positions to access universal grammar in second language learners namely (1) there is no universal grammar (2) the universal grammar exists but the several of second language learners does not have direct access it (3) the universal grammar exists also but the second language learners only can access half the universal grammar (4) the second language learners have full access to universal grammar. The second language learners have the potential to access universal grammar although is not the same with the native speakers. According to Bley-Vroman in Faharani et al the second language learners do not have direct access to universal grammar but they know the universal grammar is constructed through the first language such as when people make an analogy. They are unaware that the universal role in constructed by the first language

\section{Principles of Universal Grammar (UG)}

The universal grammar theory helps the children to enhance the natural language. The most important is the language competence depends on the experiences of language. In this article will explain the principle and parameters of UG.

There are functions of Universal grammar principles:

1) To determine the nature of language.

2) The principles of UG also help to draw the outline of grammar.

3) To analyze the grammatical construction in language. 
The principles and parameters of universal grammar more approach in syntax. When the people performance and competence in producing the language. It will now how the role of universal grammar in second language acquisition. The principles and parameters is a set of the universal grammar shared by human language. The universal principles applied the construction of the grammatical sentence. Chomsky's theory of universal grammar begins to determine how the information will be stored in the system as universal principles. There is an example of the English statement in a positive sentence and interrogative sentence.

(1) Ani will come tomorrow.

(2) Will Ani come tomorrow?

Based on the sentence above, in a positive sentence (1) the structure is subject + modals $+\mathrm{V} 1$ while the interrogative or the question formed, modals (will) should be a move to the front to make a question in English. But those sentences will easy to be disproven:

(3) The car will come tomorrow.

(4) * car the will come tomorrow?

In here also the proposed rules do not work. It should be:

(5) Will the car come tomorrow?

This involved moving the third word to the front of the sentences. If the speakers of English considered sentences as sequences of words, how will they know that to the correct question (2) the second word must be move but for the speaker to make a right question in (5) the third word should be move? The answers are the insight of language based on the insight of the internal structure in sentences. In the case above, the native speaker also knows that "Ani" (1) and "the car" (3) are corresponding constituents that are phrases that have to make the correctly in syntax structure. This case is known as structure-dependency. Structure dependency is showed it as a feature of language in all human languages. If all languages should be a move to the front when people make the interrogative sentence or questions formed. It will be awkward. So, there is a general principle in all human language.

\section{The Logical Problems of Second Language Acquisition (SLA)}

\subsection{The competence and performance}

The logical problems of second language acquisition were shown of the universal grammar theory. This part will discuss how to answer the Chomsky's question actually how is knowledge of language acquired? The problems of the second language can happen in two things namely the second language knowledge and language used. It related to the competence and performance of the second language. The adult does not have the LAD like the children. Thus, to master two languages are so hard. For the one language is enough to master for adult. Language acquisition device is a crucial component in acquiring the language but if the learner has passed a critical period. It was not totally functioning. The competence is related to what the knowledge or language exposure or intake by the learners whereas the performance related to how they use the language that they've known before. The logical problem of second language acquisition is to explain the level of competence that is clearly possible in some cases, while also permitting the wide range of variation that is observed. According to Bley (1990), there are two different components in the process of acquiring the language between the children and the adult to acquire the second language. If the children in acquiring the language, there is a role of universal grammar but the native language learners already have native language knowledge. 
The second one is the children know about the learning procedure while the people who learned the language have a general problem-solving system. In some regards, the children may know more than the native language learners because the children are completed with a general universal grammar. For example like the sun, father, mother and so on. The children know that have registers or social dialects. There are two logical problems that represented in competence and performance. Competence relates to the knowledge of the language while the performance refers to how the language use. The logical problem of the competences is interlanguage grammars. The universal grammar takes a part of the role in second language acquisition. Knowledge of language for the native speaker is represented in the mental grammar and rules. For the competence in a second language acquisition will be related to grammar. Competence will be changed over time. For example in the acquisition process, the native language learners can be said to have an internalized grammar related to current competence. People always look in second language performance and say it the different with a native speaker so that it will argue and the lack of universal grammar theory. However, competence can be hidden by performance factors such as parsing. Thus, the knowledge and how to use of knowledge are not identical notions by people.

\subsection{The Interlanguage Representation}

There are many learners are learning the second language. It surely will produce the sentence on the second language that they learned. But, the main point when they produce it that is different from how the native speaker produces the sentences or how the native speaker expresses the idea. There are two sets the utterances will have existed. According to Selinker (2009) the existence of a separate linguistic system based on the observable output which results from the learner's attempted production of a target language norm. Interlanguage also is the linguistic system of the learners when they attempt meaningful communication by using a language in the learning process (Tarone, et al., 2013; Al-khresheh, 2015; Pavesi \& Munoz, 2017). This is known as interlanguage. There are four characteristics of interlanguage representation in competence and performance in second language acquisition (1) interlanguage has three crucial things that are first language, second language and interlanguage (2) interlanguage happened naturally when learners produce second language (3) interlanguage is also constantly changing most of the time and (4) the interlanguage whether or not be fossilized. Actually, the interlanguage in second language acquisition is natural. The main point of the interlanguage is fossilization. Fossilization is claimed that it will happen when adult acquires the second language after a critical period. According to Selinker the fossilization happened because the adults who use second languages related to the general cognitive processes or generally was referred latent psychological structure rather than a universal grammar that referred to as latent language structure. There are some factors that caused to fossilization and it related how psycholinguistic process based on interlanguage. As suggested by Selinker (2009) the factors are (1) strategies of second language learning and communication (2) transfer of language (3) transfer of training and (4) generalization of target language linguistics. The learners are more attention to grammar rules or target language. As known, there are crucial processes of interlanguage in latent psychological structures. The children acquire the second language to have the ability tor reuse the universal grammar and it will help to avoid the error structure and fossilization happened when there are interlanguages of the second language learners. 


\section{The Implementation of Interlanguage Research on Second Language Acquisition}

The interlanguage implementation on second language acquisition research, it was proven by the researchers interested to find the interlanguage happened. Kang (2015) tries to find the effects of output and note-taking on noticing and interlanguage development. The learners must be attention in gaps in their knowledge and should be had successful intake. The learners in Kang's research still do errors in grammatical structure. It is caused by the influence of the second language. The research proposed by Kusumaningtyas, et al. (2018) how the children's production of interlanguage in speaking English as the foreign language and first language is Bahasa Indonesia. The researcher found more opinion on why the interlanguage phenomenon happened. The learners produce interlanguage systematically, permeable and dynamically. The learners' used strategies of second language learning and communication to anticipate the influence of the native and target language. The interlanguage happened because the learners tried to language transfer, overgeneralization and the development of grammatical of second language acquisition. The most important the main cause of interlanguage happened in learners is language transfer. Longxing (2009) also found the composite nature of interlanguage. It focuses on the lexical structure of interlanguage construction. The lexical structure is assumed to be abstract in the mental lexicon. Interlanguage performance has potential happened in learners that learned about the second language. The implementation also in research did by Afiana et al (2018) find that the permeability of students' interlanguage between Bahasa Indonesia and English. The native and target language influence students' interlanguage in vocabulary and grammar. It will effect of pedagogical implication. Interlanguage errors will also influence the teachers' positive attitude. The interlanguage happened of the learners can make the teacher also prepare and provide the appropriate training for the students to overcome the interlanguage.

The implementation of interlanguage research on second language acquisition, it is evidence that the interlanguage exists when the learners have mother tongue and learn second language acquisition. There are many researchers interested in interlanguage (e.g Kang, 2015; Longxing, 2009; Popa, 2016; Saric, 2017; Kusumaningtyas, et al., 2018). The implementation of the interlanguge on second language acquisition is generally applied in grammatical errors, how the students produce interlanguage systematically and permeable. Thus, to investigate the mistakes that students learned second language acquisition and mother tongue also can be influenced.

\section{Conclusion}

Interlanguage is a natural thing in acquiring a second language. Universal grammar generally is existing in first language acquisition but sometimes universal grammar takes a part of second language acquisition. But this is still debated. There are four different positions to access universal grammar in second language learners, namely: (1) there is not universal grammar, (2) the universal grammar exists but the several of second language learners do not have directly access it, (3) the universal grammar exists also but the second language learners only can access half the universal grammar, (4) the second language learners have full access to universal grammar. When the adults acquire a second language is related to performance and competence. In competence, they know the knowledge of this grammar but when the people produced the sentence or words. It may be grammatical is errors. There is some performance factor that the second language learners' competence is hidden such as parsing or demands of processing. It differences between pure knowledge and how people use the knowledge of its self. It may have happened interlanguage. For further research could be as a guideline, about the 
interlanguage by empirical studies so that another researcher can be proved that interlanguage was existing in acquiring the second language.

\section{References}

Al-khresheh. H.M. (2015) “A Review Study of Interlanguage Theory”. International journal of applied linguistics \& English literature vol.4 No 3 may 2015.

Afiana, D., Fauziati, E., \& Nurkamto, J. (2018). Permeability of Students' Interlanguage: A Case Study on Indonesian Students Learning English as a Foreign Language. International Journal of Scientific and Research Publications (IJSRP), 8(11), 391-394.

Bley-Vroman, R. (2012). What is the logical problem of foreign language learning? In Linguistic Perspectives on Second Language Acquisition (pp. 41-68)

Cheng, X. (2015). Interlanguage-based Error Analysis in Higher Vocational and Technological College EFL Education in China. Journal of Language Teaching and Research, 6(3), 639.

Chomsky, Noam. (1969). "Linguistics and Philosophy", in Language and Philosophy: A Symposium, Sidney Hook, (ed.), New York: New York University Press.

Farahani, A. A. K., Mehrdad, A. G., \& Ahghar, M. R. (2014). Access to Universal Grammar in Adult Second Language Acquisition. Procedia, 136, 298-301.

Fromkin, V., Rodman, R., and Hyams, N. (2007). An Introduction to Language. London: Thomson Learning.

Kang, E. Y. (2015). Effects of Output and Note-Taking on Noticing and Interlanguage Development. Working Papers in Applied Linguistics and TESOL, 10(2), 19-36.

Kusumaningtyas, YS., Rukmini, D., Fitriati, SW. (2018). Children 's Production of Interlanguage in Speaking English As The Foreign Language. English Education Journal, 8(4), 452-460

Longxing, W. (2009). The Composite Nature of Interlanguage as A Developing System. Research in language vol.7

Pavesi, M., \& Muñoz, C. (2017). Module 2: Second Language Acquisation for CLIL. Retrieved from https://www.researchgate.net/publication/242130026

Popa, S. (2016). Language transfer in second language acquisition. Some effects of L1 instruction (Romanian) on L2/L3 learning (Catalan/Spanish). TDX (Tesis Doctorals En Xarxa).

Richard, Schmidt and Kasper Gabriel. (1996). Developmental Issues in Interlanguage Pragmatics. London: Cambridge University Press

Saric, A. (2017). Developmental Patterns in the Interlanguage Research. European Journal of Social Sciences Education and Research, 6(2), 2017.

Selinker, L. (2009). INTERLANGUAGE. IRAL - International Review of Applied Linguistics in Language Teaching, 10(1-4), pp. 209-232. Retrieved 7 Oct. 2019

Tarone, E., Bigelow, M., \& Hansen, K. (2013). Literacy and Second Language Oracy. Oxford: Oxford University Press

White, L. (1989). Second Language Acquisition and Universal Grammar. Studies in Second Language Acquisition, 12(2), 121-133. https://doi.org/10.1017/S0272263100009049 